\title{
The Influence of Exercise on Depression and Psychological Well- Being Amongst Students at a Tertiary Education Campus.
}

\author{
Kathryn A Nel \\ University of Limpopo (Turfloop Campus), \\ Sovenga, Limpopo Province, South Africa. \\ Khodani L Tshikovhele \\ University of Limpopo (Turfloop Campus), \\ Sovenga, Limpopo Province, South Africa.
}

\begin{abstract}
Research using a cross-sectional survey design was conducted to determine the influence of exercise on the psychological well-being and reported rates of depression on a sample of regular exercisers and non-regular exercisers registered at a previously disadvantaged university in South Africa. Two standardised questionnaires were used to collect data from a purposive sample of 60 (30 regular exercisers and 30 non-regular exercisers), male and female (30 females and 30 males) undergraduate students. Data were analysed using descriptive statistics. A Chi Square test was used to find out if there were any significant relationships between the regular exercisers and nonregular exercisers and male and female participants, in terms of depression and psychological well-being. Students who exercised regularly reported a positive psychological well-being while non-regular exercisers showed a more negative psychological well-being. There were no significant differences in reported feelings of depression across the male and female sample of regular and non-regular exercisers. Regular exercisers however, showed more positive psychological well-being than nonexercisers which was a significant result $(\mathrm{p}=\mathbf{0 . 0 0 1})$.
\end{abstract}

\section{INTRODUCTION}

The prescription rates for anti-depressants medication have increased exponentially in the last decade. However, anti-depressants are not always effective and they always have some sideeffects. Psychological therapies such as Cognitive Behavioural Therapy (CBT) are available but in Europe waiting lists in state institutions are long [1]. This is mirrored in South Africa where waiting lists are long at state hospitals and the majority of the populace cannot afford private treatment.

If depression is mild to moderate physical activity is recommended as an alternative treatment approach. It can be used as a stand-alone treatment or in combination with medication and/or psychological therapy. It has very few side effects, unless the individual has other medical ailments, and does not have the stigma that is attached to taking anti-depressants or attending psychological therapy [1]. However, not everyone agrees that evidence for the benefits of physical activity is effective in treating depression [2].

Exercise improves depressive symptoms when compared with no treatment or a controlled intervention. However, the effect of exercise on clinical depression revealed that the effectiveness of physical activity as a treatment for depression is likely to vary in relation to the severity of the depression [3]. Three trials that compared exercise with anti-depressant medication found no significant difference in the effect of the two treatment approaches [4]. It 
has also been found that exercise is effective when used independently and in combination with other treatments such as medication or Cognitive Behavioural Therapy (CBT) [5]. Physical activity was compared by a research team in terms of different doses. It was concluded that high doses of physical activity were more effective than low doses $(28 \%$ and $15 \%$ reduction rate respectively) in preventing and relieving depressive symptomology [6]. The vast majority of published trials, which have found a positive effect for physical activity in treating depression are linked to aerobic physical activity (any activity that can be sustained continuously using large muscle groups), such as aerobic classes or using a treadmill [7].

Furthermore, all modes of physical activity, no matter what their location (home or gym) were found to be just as effective in relieving depression. Individual and group physical activity were similarly effective in helping alleviate different facets of depression [8]. The implications of the aforementioned research indicate that public health guidelines (in most developed countries) for physical activity offer greater benefits for health as compared to lower levels of physical activity [8].

Mental health problems continue to present a global challenge affecting more than 120 million people worldwide $[9 ; 10]$. It is predicted that depression will become the highest cause or burden of disease by the year 2020 [11].

Exercise is one of the most under-endorsed treatments for people with mild to moderate depression. It has been shown to lessen depression, anxiety, and Post-Traumatic Stress Disorder (PTSD), improve cognitive function and self-esteem. These effects are neuropsychochemical in nature because exercise encourages the secretion of neurotransmitters such as serotonin, adrenaline and endogenous opiates [12].

However, in practice even mild depression is often treated with medication and/or psychotherapy. The addition of appropriate fitness exercise programmes in treatment approaches may well allow the symptoms of depression to be treated more holistically. In this scenario a depressed individual would be able to participate more fully in his or her treatment rather than being passive in traditional processes. It must be noted that exercise should be medically appropriate and is not indicated in cases of severe depression [13].

Psychological well-being and the physical self-perception of persons who frequently take part in various forms of physical activity, exercise and sport was compared with a control group of non-exercisers. Different physical activities included health club exercisers, hockey players and running. Findings suggested that individuals engaging in regular physical activity reported more autonomy, personal growth, environmental mastery, purpose in life, positive relations with others, self-acceptance and sport competence than non-exercisers. Those who exercised consistently also attached added importance to sport generally than non-exercisers [14].

The relationship between exercise and psychological well-being is widely recognised as a key factor in determining global personal and public health, with physical activity ever more recommended as a means of addressing incapacitating psychological problems such as depression and many other physical health conditions (for instance, hypertension). Exercise, appropriately recommended also offers individuals an opportunity to play an active role in their recovery from many different illnesses $[12 ; 15 ; 16]$.

The researchers in this investigation studied the impact of exercise on both the psychological well-being and depression levels of a sample of tertiary education students at a previously disadvantaged institution in South Africa. 


\section{METHOD}

The research approach was quantitative and descriptive in nature and utilising a crosssectional survey design.

\section{Sampling}

In this study non-proportional quota sampling was used. This method is the nonprobabilistic equivalent of stratified random sampling. It is typically used for smaller groups which meet specific criteria to ensure that all strata are adequately represented in a sample. The population consisted of a) all registered undergraduate students who participated in a sporting code and who exercised regularly and b) all registered undergraduate students who did not participate in any sport or exercise activity at all.

Undergraduate students who did not participate in any exercise activities were found in $1^{\text {st }}, 2^{\text {nd }}$ and $3^{\text {rd }}$ year undergraduate classes. At each level the researcher asked for volunteers to participate in the research (5 females and 5 males at each level to ensure gender representativeness). The active or exercising students were found through approaching the Director of Sports at the institution. Participants were undergraduates' students from levels $1^{\text {st }}$, $2^{\text {nd }}$ and $3^{\text {rd }}$ year levels who participated in regular exercise (sport).

A final sample of 30 students who were non-regular exercisers (did not exercise at all) which consisted of (15 females and 15 males) and 30 students who exercised the designated level (15 females and 15 males) was considered appropriate, as it was difficult to find a larger sample of males and females who exercised according to the required inclusion criteria.

\section{Inclusion criteria}

a) All registered undergraduate students (male and female) who exercised as defined for the purposes of this study. Exercise referred to any physical exercise which was undertaken on a regular basis that is, three times a week for about thirty minutes over a period of two months or more [17].

b) The sample of non - regular exercisers was defined as those who did not take part in any physical sporting code or participate in any fitness activities. Participants were male and female.

\section{Exclusion criteria}

a) Students who were previously diagnosed with any form of depression.

b) Students who could not exercise due to a medical/physical and/or psychiatric condition.

c) Students who took chronic medication for any psychological/psychiatric and/or medical condition.

\section{Data collection}

Data were collected from the two groups namely, the regular exercise group and the control group of those who did not exercise at all. The data were collected by means of self-report questionnaires. The researchers asked participants to fill in the questionnaire after, or before they trained (their choice) and collected them thereafter if they participated in. Those who did not exercise at all filled in the questionnaires after lectures.

\section{Study instruments}

The Becks Depression Inventory (BDI - 11) - The BDI - 11 is used to screen for the presence and intensity of depression. It is a 21 item self-report rating inventory measuring characteristic 
attitudes and symptoms of depression. It was self-administered and tool about ten minutes to complete. The BDI - 11 has been found to be valid and reliable in a South African context [18].

The BDI - 11 has high levels of internal consistency ranging from .73 to .92 with a mean of .86 [19]. The Cronbach Alpha coefficients were found to be .86 and .81 for psychiatric and nonpsychiatric populations, respectively. Test re-test reliabilities range from .48 to .86, depending on the interval between re-testing and the type of population [20].

\section{The Psychological Well-Being Scale}

The Psychological Well-Being Scale was standardised by comparing it with subjective measures of psychological well-being (life satisfaction, positive and negative [21; 22; 23]. The six subscales have high levels of internal consistency (Cronbach Alpha): positive relations with others .88; autonomy .83; environmental mastery .86; personal growth .85; purpose in life .88 and self-acceptance .91 [22].

\section{Data analysis}

The study used descriptive statistics to give a clear picture of the data. The Chi Square $\left(\mathrm{X}^{2}\right)$ statistic was used to investigate whether distributions of categorical variables differ from one another. In this study the test was employed to determine the relationship between regular and non-regular exercisers and depression and psychological well-being.

\section{Research proposition}

The research proposition for the study was: The influence of exercise reduces self-reported feelings of depression and increases the feelings of psychological well-being of undergraduate students registered at the tertiary institution.

\section{Ethical considerations}

Informed consent was obtained from all respondents and confidentiality observed throughout the research. Limits to confidentiality were explained as was the rationale for the investigation. Permission to conduct the research was gained through the institutional Research and Ethics Committee.

\section{RESULTS AND DISCUSSION}

This study focused on $1^{\text {st }}, 2^{\text {nd }}$ and $3^{\text {rd }}$ undergraduate students at the institution. There were 60 respondents ( 30 males and 30 females) aged 18 to 30 years $(M=21.2$ yrs: $S D=1.809$ ).

Table 1: Regular exercisers (sports) versus non- regular exercisers

\begin{tabular}{lll}
\hline & Frequency & Percent (\%) \\
\hline Rugby & 10 & 16.7 \\
Hockey & 10 & 16.7 \\
Soccer & 10 & 16.7 \\
Non- & & \\
exercisers & 30 & 16.7 \\
\hline \multicolumn{1}{c}{ Total } & 60 & $100 \%$
\end{tabular}

The majority of students who exercised regularly reported minimal feelings of depression and had feelings of positive psychological well-being whereas students who did not exercise regularly reported higher feelings of depression and negative psychological well-being. 
Table 2: Reported depression in male and female exercisers and non-regular exercisers

\begin{tabular}{|c|c|c|c|c|c|c|c|}
\hline \multirow{2}{*}{ Sport } & & & \multicolumn{4}{|c|}{ Depression } & \multirow[b]{2}{*}{ Total } \\
\hline & & & Minimal & Mild & Moderate & Severe & \\
\hline \multirow[t]{3}{*}{ Regular exercisers } & Gender & Male & 15 & & & & 15 \\
\hline & & Female & 15 & & & & 15 \\
\hline & Total & & 30 & & & & 30 \\
\hline \multirow{3}{*}{$\begin{array}{l}\text { Non - regular } \\
\text { exercisers }\end{array}$} & Gender & Male & 2 & 5 & 6 & 2 & 15 \\
\hline & & Female & 3 & 3 & 8 & 1 & 15 \\
\hline & Total & & 5 & 8 & 14 & 3 & 30 \\
\hline \multirow[t]{3}{*}{ Total } & Gender & Male & 17 & 5 & 6 & 2 & 30 \\
\hline & & Female & 18 & 3 & 8 & 1 & 30 \\
\hline & Total & & 35 & 8 & 14 & 3 & 60 \\
\hline
\end{tabular}

Exercisers have the requisite motivation and behaviour patterns which are requirements for independence and competence in relation to healthy human functioning [24]. However, nonexercisers displayed amotivational behaviours (by not participating in exercise at all) which is likely to lead to an unhealthier lifestyle for instance, an earlier decline in cognitive function or obesity [25]. However, it must also be noted that a few students who exercised regularly (7 or $23.3 \%$ ) reported minimal depression, which is equivalent to normal or non - clinical depression.

The students who were not regular exercisers showed more negative psychological well-being and reported more feelings of depression, which is a challenge for them when coping with academic (for instance, exams) and social life (for instance, peer group relationships) on campus. Females reported more positive psychological well-being than males in the study, the reason for this needs further exploration.

Table 3: Overall exercise and psychological well-being (level of significance $\mathbf{p} \leq \mathbf{0 0 . 0 5}$ )

\begin{tabular}{|c|c|c|c|c|c|}
\hline & Value & df & $\begin{array}{l}\text { Asymp. Sig. } \\
\text { (2-sided) }\end{array}$ & $\begin{array}{c}\text { Exact Sig. (2 } \\
\text { sided) }\end{array}$ & $\begin{array}{l}\text { Exact Sig. (1- } \\
\text { sided) }\end{array}$ \\
\hline Pearson Chi-Square & 11.380 & 1 & .001 & \multirow{6}{*}{.002} & \multirow{6}{*}{.001} \\
\hline Continuity Correction & 9.697 & 1 & .002 & & \\
\hline Likelihood Ratio & 11.789 & 1 & .001 & & \\
\hline Fisher's Exact Test & & & & & \\
\hline Linear-by-Linear & 11.191 & 1 & .001 & & \\
\hline & 60 & & & & \\
\hline
\end{tabular}

Overall, males and females who exercised regularly showed no significant difference in terms of reported depression. This does not concur with the Diagnostic and Statistical Manual of Psychological Disorders (DSM - 5, 2013) which reports that females are more likely to report depression than males [26], however the sample size was small which must be taken into account. There was a significant difference amongst exercisers and non-exercisers in relation to exercise having a positive impact on depression and psychological well-being. 
Table 4: Levels of depression across the entire sample of exercisers versus non- regular exercisers (level of significance $\mathbf{p} \leq \mathbf{0 0 . 0 5}$ )

\begin{tabular}{|rl|r|r|r|c|c|}
\hline Depression & \multicolumn{1}{|c|}{ Value } & $\mathrm{df}$ & $\begin{array}{c}\text { Asymp. Sig. } \\
\text { (2-sided) }\end{array}$ & $\begin{array}{c}\text { Exact Sig. (2- } \\
\text { sided) }\end{array}$ & $\begin{array}{c}\text { Exact Sig. (1- } \\
\text { sided) }\end{array}$ \\
\hline depression & N of Valid Cases & 3 & & & & \\
& Pearson Chi-Square & 11.380 & 1 & .001 & & \\
& Continuity Correction & 9.697 & 1 & .002 & & \\
& Likelihood Ratio & 11.789 & 1 & .001 & & .001 \\
& Fisher's Exact Test & & & & .002 & \\
& Linear-by-Linear & 11.191 & 1 & .001 & & \\
Association & 60 & & & & \\
N of Valid Cases & & & & \\
\hline
\end{tabular}

CONCLUSION

Overall the research proposition which stated the influence of exercise reduces self-reported feelings of depression and increases the feelings of psychological well-being was supported. Research in South Africa of a similar nature [17; 21;27;) underpins the results and conclusions of the present study namely that exercise enhances psychological well-being which in turn reduces feelings of anxiety, stress related to depression. Most international studies support the fact that exercise reduces feelings of depression and increases psychological well-being in communities, universities, amongst mature adults, students, elderly or mentally ill patients $[28 ; 29 ; 30]$.

Negative side effects are few but are indicated in individuals with exercise dependence and are usually related to eating disorders [31]. In the present study students who exercised regularly did benefit positively in terms of overall well-being and none reported what the researchers could interpret as exercise dependence, and had less indicators of moderate to severe depression than those who did not exercise regularly.

\section{RECOMMENDATION ARISING OUT OF THE STUDY}

A factor that hinders non-exercisers from exercising is motivation. Motivation is required for individuals to want to participate in any physical activity. Lack of motivation can be explained by insufficient interest, lack of knowledge about the value of exercise outcomes and competing demands on their time [25]. Lack of knowledge about the benefits of exercise can be remedied through interventions during $1^{\text {st }}$ year orientation and presentations by sports clubs throughout the year.

\section{LIMITATIONS OF THE STUDY}

The sample was small and not randomised thus inferential statistics could not be used and findings could not be generalised

\section{References}

Kirsch, I., Deacon, B. J., Huedo-Medina, T. B., Scoboria, A., Moore, T. J., \& Johnson, B.T. (2008). Initial Severity and Anti-Depressants Benefits: A Meta-Analysis of Data Submitted to the Food and Drug Administration. PLoS Medicine, 5(2) 45.

Chalder, M., Wiles, N.J., Campbell, J., Hollinghurst, S.P., Haase, A.M., Taylor, A.H., Fox, K.R., Costelloe, C., Searle, E., Baxter, H., Winder, C., Wright., C., Turner, K.M., Calnan, M., Lawlor, D.A., Peters, T.J., Sharp, D.J., Montgomery, A.A., \& Lewis, G. (2012). Facilitated physical activity as a treatment for depressed adults: randomised controlled trial. $B M J, 6,344-350$. 
Nel, K. A., \& Tshikovhele, K. L. (2018). The Influence of Exercise on Depression and Psychological Well-Being Amongst Students at a Tertiary Education Campus. Advances in Social Sciences Research Journal, 5(2) 146-153.

Krogh, J. Nordentoft, M., Sterne, J. A., \& Lawlor, D. A. (2011). The effect of exercise in clinically depressed adults: systematic review and meta-analysis of randomized controlled trials. Journal of Clinical Psychiatry, 72(4), 529-38.

Rimer, J., Dwan, K., Lawlor, D., Greig, C., McMurdo, M., \& Morley, W. (2012). Exercise for depression. Cochrane Database of Systematic Reviews, 7.

Perraton, L. G., Kumar, S., \& Machotka, Z. (2010). Exercise parameters in the treatment of clinical depression: a systematic review of randomized controlled trials. Journal of Evaluation in Clinical Practice, 16(3). 597-604.

Trivedi, M. H., Greer, T. L., Church, T. S., Carmody, T. J., Grannemann, B. D. \&, Galper, D. I. (2011). Exercise as an augmentation treatment for non-remitted major depressive disorder: a randomized, parallel dose comparison. Journal of Clinical Psychiatry, 72(5), 677-84.

Perraton, L. G., Kumar, S., \& Machotka, Z. (2010). Exercise parameters in the treatment of clinical depression: a systematic review of randomized controlled trials. Journal of Evaluation in Clinical Practice, 16(3). 597-604.

Callaghan, P., Khalil, E., Morres, I., \& Carter, T. (2011). Pragmatic randomised controlled trial of preferred intensity exercise in women living with depression. BMC Public Health, 11(1), 465.

Blake, H. (2012). Physical activity and exercise in the treatment of depression. Front Psychiatry, 3: 106.

WHO (2013). World Health Organisation: depression anxiety and stress. Retrieved from http://www.who.int/mediacentre/factsheets/fs369/en/

Moussavi, S., Chatterji, S., Verdes, E., Tandon, A., Patel, V., \& Ustun B. (2007). Depression, chronic diseases, and decrements in health: results from the World Health Surveys. Lancet, 370, 808.

Sadock, B. J., \& Sadock, V.A. (2007). Synopsis of Psychiatry. Philadelphia: Lippincott.

Edwards, S. (2006). Physical exercise and psychological well-being. Retrieved from http://sap.sagepub.com/content/36/2/357

Edwards, S.D., Ngcobo, H.S.B., Edwards, D., \& Palavar, K. (2005). Exploring the relationship between physical activity, physical activity, psychological well-being and self-perception in different exercise groups. South African Journal for Research in Sport, Physical Education and Recreation, 27(1), 75-90.

Edwards, S.D. (2004). Mental health, physical activity and public health: a South African perspective. Paper presented at the Third World Congress of Mental Health Promotion in Auckland New Zealand.

Lawlor, D. A., \& Hopker, S. W. (2001). The effectiveness of exercise as an intervention in the management of depression: systematic review and meta-regression analysis of randomised controlled trials. BMJ, 322,1 - 8.

Edwards, S. (2002). Promoting mental health through physical exercise. UZ Journal of Psychology, 1(16), 18-22.

Pillay, A. L., Edwards, S., Gambu, S.Q., \& Dhlomo, R. M. (2002). Depression among university students in South Africa. Psychological reports, 91, 725-728.

Beck, A.T., \& Steer, R.A., \& Garbin, M.G. (1988) Psychometric properties of the Beck Depression Inventory: twentyfive years of evaluation. Clinical psychology Review, 1(8), 77-100.

Groth-Marnat, G. (1990). The handbook of psychological assessment. New York: John Wiley and Sons.

Edwards, S., Edwards, D., \& Basson, C. (2004). Psychological well-being and physical self-esteem in sport and exercise. The international journal of mental health promotion, 6(1), 25.

Ryff, C. (1989). Happiness is everything, or is it? Explorations on the meaning of psychological well-being. Journal of Personality and Social Psychology. 57(6), 1069- 1081.

Schmutte, P. S., \& Ryff, C. D. (1997). Personality and well-being: what is the connection? Journal of Personality and Social Psychology. 73, 549-559.

Teixeira, P. J., Carraça, E. V., Markland, D., Silva, M. N., \& Ryan, R. M. (2012). Exercise, physical activity, and selfdetermination theory: A systematic review. International Journal of Behavioral Nutrition and Physical Activity, 9, 78.

Ryan, R. M., Williams, G. C., Patrick, H., \& Deci, E.L. (2009). Self-determination theory and physical activity: The dynamics of motivation in development and wellness. Hellenic Journal of Psychology, 6,107-124.

DSM - 5 (2013). Diagnostic and statistical manual of mental disorders (5 $5^{\text {th }}$ Ed.). Washington, DC: APA publishers.

Bydawell, L. (2005). The impact of exercise on depression and psychological well-being. Retrieved from

http://www.uzspace.uzulu.ac.za/handle/10530/333 
Carek, P.J., Laibstain, S.E., \& Carek, S.M. (2011). Exercise for the treatment of depression and anxiety. Int J Psychiatry Med, 41(1), 15-28.

De Moor, M. H., Boomsma., D. I., Stubbe, J. H., Willemsen, G., \& de Geus, E. J. (2008). Testing causality in the association between regular exercise and symptoms of anxiety and depression. Arch Gen Psychiatry, 65, 897905.

Morgan, A. J., Parker, A.G., Alvarez-Jimenez, M., \& Jorm, A. F. (2013). Exercise and Mental Health. Exercise and Sports Science Australia, 16(4):64-73.

Freimuth, M., Moniz, S., \& Kim, S. R. (2011). Clarifying Exercise Addiction: Differential Diagnosis, Co-occurring Disorders, and Phases of Addiction. International Journal of Environmental Research and Public Health, 8(10), 4069-81. 